\title{
Entre o ocaso do Império e a afirmação da República no Brasil: mudança institucional gradual e transformativa
}

\author{
Diego Mota Vieira \\ Universidade de Brasília \\ Leonor Moreira Câmara \\ Universidade de Brasilia \\ Ricardo Corrêa Gomes \\ Universidade de Brasilia
}

\begin{abstract}
Este ensaio descreve o processo de consolidação da República no Brasil, demonstrando que o caso ilustra a mudança transformativa das instituições políticas por meio da ação de grupos de interesse. Pretende-se contribuir para preencher duas importantes lacunas teóricas. Por um lado, a escassez de teorização sobre a administração pública brasileira com enfoque histórico e não instrumental. Por outro lado, o atual debate no Novo Institucionalismo acerca dos processos de mudança institucional. Assim, o trabalho apresenta como principais resultados a identificação e classificação das estratégias das elites republicanas que rotinizaram a administração pública brasileira, ao mesmo tempo que consolidaram o novo regime político.
\end{abstract}

Palavras-chave: administração pública; novo institucionalismo; mudança institucional; governo Campos Sales; grupos de interesse.

La transición de la monarquía al Estado republicano en Brasil: cambio institucional gradual y transformador

Este trabajo describe el proceso de consolidación de la República en Brasil. Demuestra que el caso ilustra el cambio transformador de las instituciones políticas a través de la acción de los grupos de interés. Su objetivo es contribuir a dos lagunas teóricas importantes. Por un lado, la falta de teorización sobre la administración pública brasileña con un enfoque histórico y no instrumental. Por otra parte, el debate actual en el nuevo institucionalismo sobre los procesos de cambio institucional. Por lo tanto, el documento presenta los principales resultados de la identificación y clasificación de las estrategias que las elites republicanas rotinizaran para la administración pública brasileña al mismo tiempo que consolidaran el nuevo régimen político.

Palabras clave: administración pública; nuevo institucionalismo; cambio institucional; gobierno Campos Sales; grupos de interés.

DOI: http://dx.doi.org/10.1590/0034-76121435

Artigo recebido em 17 jan. 2013 e aceito em 12 fev. 2014.

Rev. Adm. Pública - Rio de Janeiro 48(3):531-550, maio/jun. 2014 
Between the decline of the Empire and the affirmation of the Republic in Brazil: gradual and transformative institutional change

This essay describes the process for consolidating the Republic in Brazil, showing that the case illustrates the transformative change of political institutions through the action of interest groups. We intend to contribute to bridge two important theoretical gaps. On the one hand, the lack of theorizing about the Brazilian public administration with a historical and non-instrumental approach. On the other hand, the current debate in New Institutionalism about the institutional change processes. Thus, the paper has as its main results the identification and classification of strategies of the republican elites that provided the Brazilian public administration with routines, at the same time that they consolidated the new political regime.

KeYworDs: public administration; new institutionalism; institutional change; Campos Sales administration; interest group.

\section{Introdução}

Entre o ocaso do Império e a afirmação da República, o Brasil passou por um período de mudança institucional gradual e transformativa. Apropriando-se do modelo de Mahoney e Thelen (2010), percebe-se que, em um primeiro momento, a mudança institucional gradual do tipo "substituição" proporcionou a alteração do regime político. Entretanto, para consolidá-lo, novas mudanças do tipo "por camadas" ocorreram viabilizando também a organização da administração pública no país.

O presente ensaio pretende contribuir para a discussão em voga no novo institucionalismo a respeito de mudança institucional. Além disso, busca preencher uma lacuna nos estudos em administração pública ao adotar uma postura não instrumental, num esforço de teorização sobre um importante período da história do Estado brasileiro.

Para alguns autores (Schmidt, 2008; Thelen, 2009; Mahoney e Thelen, 2010; Bell, 2011), as perspectivas histórica, sociológica e da escolha racional do novo institucionalismo tendem a privilegiar um olhar dedicado ao continuísmo e à reprodução das instituições, entendidas, segundo Scott (1995:xiii; tradução livre), como "estruturas e atividades cognitivas, normativas e reguladoras que proveem estabilidade e significado ao comportamento social". Negligenciando os processos de mudança desencadeados pela força da agência, observa-se a mudança de forma descontinuada, com períodos de estabilidade ocasionalmente perturbados por alguma força exógena que provoca momentos de agência e escolha, seguida novamente por outro período de cômoda estabilidade (trajetórias históricas como legados desses momentos críticos, conforme o modelo de equilíbrio pontuado de mudança).

Entretanto, a estabilidade institucional é função não apenas da conformação dos atores, mas também da mobilização política ativa e contínua. Essa postura ativa em relação às instituições pode provocar também a mudança institucional de forma gradual e transformativa. Ora, considerando-se que as instituições são instrumentos distributivos de poder e de recursos, é possível vislumbrar a ação dos agentes de modo a gerar um contexto que lhes seja 
favorável. Nesse sentido, são sinalizadas disputas entre grupos com interesses distintos e entre aqueles que almejam e os que estão exercendo o poder (Mahoney e Thelen, 2010). Portanto, conforme aponta Bell (2011), tem-se que os atores confrontam as instituições caso não percebam uma situação satisfatória para si.

No Brasil, entre o ocaso do Império e a afirmação da República, grupos interessados posicionaram-se ativamente diante das instituições promovendo um processo de mudança institucional do tipo gradual e transformativa. Antes, à margem do poder lutando para mudar o sistema político do país e, depois, como coalizão dominante lutando para sustentar a mudança, republicanos civis e militares acabaram por proporcionar a estabilidade da República e a organização da administração pública brasileira.

Salienta-se que o Estado, no Brasil, nasceu e se consolidou como Estado monárquico. A República herdou da Monarquia um Estado organizado de modo centralizado e já com alguma tradição burocrática (Uricoechea,1978). Entre os maiores expoentes do ideal centralizador do Estado encontram-se os juristas, em especial o visconde do Uruguai (Carvalho, 2002). Contudo, destaca-se que, segundo Carvalho (2003), os militares também expressaram, no final do Império e início da República, preocupações centralizadoras, uma visão de unicidade do poder. Lessa (2001) e Carvalho (2005) chegam a considerar uma verdadeira tradição originada no Império a verticalização da ordem política e sua instrumentalização, inspiradas no direito administrativo francês.

Por outro lado, a reorganização da comunidade política com base em novos valores republicanos impôs desafios tremendos aos republicanos vitoriosos que, além do cientificismo garantidor de estabilidade e eficácia segundo o ideal positivista, consideravam também atitudes cívicas como ideais de poder (Lafer, 1989; Carvalho, 1990). O contexto era de grandes transformações sociais como a disseminação do mercado de trabalho, o final da escravidão, as ondas migratórias e de definições nas relações financeiras do país com o exterior (Franco, 1992).

Há que se considerar ainda que o positivismo, mais precisamente, "certa leitura positivista da República (...) enfatiza, de um lado, a ideia de progresso pela ciência e, de outro, o conceito de ditadura republicana, que contribuía poderosamente para o reforço da postura tecnocrática e autoritária" (Carvalho, 1987:35). Ainda que a proclamação da República não tenha implicado imediatamente grandes transformações na organização interna do Poder Executivo, a Constituição de 1891 é paradigmática a respeito, pois já contém a ideia de um ordenamento institucional pautado num arranjo racional-legal (Vianna, 2001:112).

O estudo da organização da administração pública durante a Primeira República é relevante para a compreensão da dinâmica que caracterizará as estruturas do Estado depois da Revolução de 1930. Trata-se de foro privilegiado para a realização de estudos acerca da ação de organizar a administração pública federal brasileira e de sua dinâmica, sobretudo de aspectos relacionados à permanência e à transformação de seus arranjos organizacionais. A administração pública na Primeira República como problema de pesquisa em estudos organizacionais revela-se paradoxal. Parte integrante da Política dos Estados aplicada por Campos Sales (1898-1902) pauta-se no princípio republicano da não intervenção nos estados levado 
ao extremo, mas tem-se, pari passu, a concentração dos meios de administração organizados burocraticamente e centralizados na figura do presidente. O contexto é o do remanejamento de recursos de poder, com base no uso ideológico da dicotomia política versus administração enquanto fundamento de legitimidade e da definição do governo como instrumento de administração.

A partir do governo Campos Sales, a República sofreu um processo de rotinização que combinava (ou buscava combinar) o máximo de eficácia administrativa com o máximo de autonomia das elites regionais. Esse processo obteve um status de legitimidade que permitiu a institucionalização da República, ou seja, o estabelecimento de procedimentos e valores legítimos que propiciaram estabilidade e continuidade ao novo regime político. Aliás, os primeiros anos da República devem ser considerados de risco para a sua continuidade, dada uma possível fragilidade em relação a eventos exógenos ou endógenos que viessem a proporcionar alternativas que não o regime republicano, como uma reação dos monarquistas, a insatisfação popular ou o descontentamento militar.

Após o golpe republicano em 1889, a primeira década do novo regime é reconhecida como a década do caos, ou como anos entrópicos. Isto porque é "caracterizada, além da ausência de mecanismos institucionais minimamente rotinizadores, pelo comportamento errático dos atores, que, no tratamento das fontes de instabilidade, acabaram por introduzir ainda mais incerteza e confusão" (Lessa, 1999:27). Pode-se então dizer que somente uma década depois registram-se a gênese e a implantação da ordem política republicana, tomando como evidência e passo inicial a fórmula política aplicada no governo do presidente Manoel Ferraz de Campos Sales, entre 1898 e 1902.

Isto posto, cabe ressaltar que a produção de conhecimentos acerca da administração pública, numa perspectiva não instrumental, não linear nem evolucionista, apresenta-se como desafio para o campo de estudos organizacionais (EOs). Isto porque a administração pública no Brasil é tida como subárea da administração, o que favoreceria, entre outras, entende-se, visões instrumentais focadas na noção de eficiência econômica tradicionalmente hegemônicas na área. De modo geral, observa-se como característica do campo a baixa capacidade de teorização dos autores nacionais em associação à grande influência da produção de conhecimento originada de outros países. É o que demonstram Rodrigues e Carrieri (2001), Hemais e Vergara (2000), Vergara (2001), Vergara e Pinto (2001), Hemais e Vergara (2001), Motta, Alcadipani e Bresler (2001), Fischer (2003) e Vergara e Carvalho (1995).

Já no que diz respeito à dimensão pública de EOs, têm-se obstáculos que extrapolam fronteiras. A partir de uma visão que não considera nacionalidades, Thoenig (2007) considera a produção de conhecimentos sobre a dimensão pública das organizações bastante limitada. $\mathrm{O}$ autor destaca os desafios de se construir uma abordagem que considere as organizações públicas como fenômeno específico. Para o autor, esse seria um passo fundamental para os impasses atuais do estudo da dimensão pública no contexto de estudos organizacionais.

Entende-se que os desafios propostos por Thoenig (2007) aplicam-se também à produção nacional. Misoczky (2004) fala da realidade da pesquisa no Brasil, em específico, com 
relação à administração pública, o que incluiria a dimensão pública de EOs, com ênfase na colonização do campo por valores da gestão empresarial e na fragilização de sua dimensão política. A autora destaca a escassez de teorização. As reflexões existentes estariam, por serem importadas, descontextualizadas das práticas e tenderiam a "naturalizar" os modos de organização da administração ou, mais precisamente, seus arranjos de poder.

Além das fragilidades epistemológicas que caracterizam a produção de conhecimentos destacadas, a ausência de estudos sobre a administração pública no período em tela constitui mais um desafio. Por esse motivo, como estratégia metodológica, optou-se por explorar na construção do caso a perspectiva de Renato Lessa, em sua obra $A$ invenção republicana, cuja primeira edição data de 1999. Corrobora com a escolha da obra o fato de apresentar visão convergente com os pressupostos do neoinstitucionalismo histórico, a mesma que respalda este trabalho. Logo, assim como em outros trabalhos que tratam da mudança institucional gradual e transformativa a partir do modelo proposto por Streeck e Thelen (2005), como a obra de Falleti (2010), apresenta-se o caso em uma perspectiva histórica e então procede-se a um esforço de interpretação à luz do modelo teórico.

Portanto, no que diz respeito à estrutura do trabalho, em primeiro lugar é feito um relato sobre o legado monarquista e os primeiros anos da República. Na sequência, trata-se da formulação e das características da Política dos Estados com foco na organização da administração pública. Posteriormente, discute-se o modelo de mudança institucional gradual e transformativa adotado neste trabalho. O ensaio então é concluído com a aplicação do modelo teórico como ferramenta para a análise do processo de consolidação da República e da organização da administração pública no Brasil, sugerindo-se, também, futuros direcionamentos de pesquisa a partir das construções apresentadas até aqui.

\section{Os anos entrópicos da Primeira República}

Próxima de seu fim, a monarquia brasileira caracterizava-se pela hipercentralização políticoadministrativa, pelo controle da dinâmica legislativa e pela regulação do mercado político via legislação eleitoral. Não obstante, observava-se um padrão estável de exclusão do demos, pautado num rígido controle sobre a formação de atores políticos coletivos e na homogeneidade da elite em termos de origem e inserção no arranjo institucional (Lessa, 1999). Ao relatar como se deu a proclamação da República e ao caracterizar seus primeiros anos, espera-se já estabelecer um contexto apontando quem eram e como agiam os atores interessados que protagonizariam o processo de mudança institucional.

Isto posto, observa-se que, ao contrário das agitações separatistas do período regencial, a propaganda republicana, no fim do Império, era domesticada e circunscrevia-se à Corte e a São Paulo. Lessa (1999:70) descreve assim a proclamação da República:

O Brasil acordou sem Poder Moderador em 16 de novembro de 1889. Isto é, sem ter qualquer resposta institucional a respeito de si mesmo: quem faz parte da comunidade política, como se- 
rão as relações entre pólis e demos, entre poder central e as províncias, como se organizarão os partidos e como se definirão as identidades políticas. Enfim, sobre quem deverá mandar.

A instituição da República é caracterizada pelas ausências do povo, de reação monarquista e de um programa consistente de unidade dos republicanos vitoriosos. Reflete, em outras palavras, em tese, o intento de abandono dos critérios monárquicos de organização do espaço público sem que algo concreto fosse colocado em seu lugar (Lessa, 1999; Carvalho, 1987). A República teria pela frente um período de indefinições relacionadas ao arranjo institucional capaz de acomodar os interesses sociais das elites, situados, sobretudo, na oposição à centralização político-administrativa que caracterizou o Império.

Os primeiros anos da República, chamados de anos entrópicos, foram marcados pela ausência de mecanismos institucionais rotinizadores, pelo comportamento errático de seus principais atores, pelas relações conflituosas entre governo central e estados e pela influência política das Forças Armadas. Lessa (1999:27-28) fala da ideia de absurdo e de tragédia:

A ideia de absurdo se aplica a um contexto no qual a experiência vivida pelos atores não é representada como experiência comum, e sim marcada pela superposição de inúmeros sentidos, projetos e versões a respeito do que se passa, sem que haja qualquer mecanismo de integração (...). A ideia de tragédia aparece como apropriada na medida em que os anos entrópicos apresentam a seus protagonistas uma dilatada quantidade de desafios, impedindo a qualquer dos atores a posse de um mapa cognitivo capaz de erradicar a ignorância sobre o que se passava.

Durante o governo provisório do marechal Deodoro (15-11-1889 a 23-2-1891), é estabelecido o presidencialismo com a indissolubilidade do Poder Legislativo. O governo provisório buscava a desrotinização da política, ou seja, reconstruir os mecanismos de poder nos estados e subordiná-los a uma ordem nacional. Entretanto, com forte presença militar, ele sofreu com a baixa institucionalização dos mecanismos de governo, com a anarquia estadual decorrente dos impasses da opção federalista e da hiperpolitização das Forças Armadas. Após a primeira Assembleia Constituinte realizada em novembro de 1890, tem-se que os principais ingredientes da República constitucional eram: a opção federalista com presidencialismo; as atribuições dilatadas do Legislativo; a imprecisão nas relações políticas entre União e estados; a maior concentração de tributos nos estados; a asfixia política dos municípios; e a relativa obediência das Forças Armadas (Lessa, 1999). Procurava-se então responder a uma demanda pela descentralização política, pela redistribuição do poder no interior da pólis e pela diminuição do tamanho do governo central.

A relação conflituosa existente entre governo central e estados e que se repetia entre os Poderes Executivo e Legislativo durou além do governo provisório de Deodoro. Mesmo após sua queda, os conflitos prosseguiram no governo de Floriano Peixoto (Lessa, 1999). O Executivo não conseguiu intervir com sucesso nos estados, impossibilitando a formação de atores coletivos dotados de alguma identidade política mais permanente. Havia ainda oposição entre militares e civis, entre militares jacobinos e legalistas, entre Exército e Marinha e entre federa- 
listas e hiperfederalistas. Segundo Guanabara (2002:19), considerando-se os governos de Floriano Peixoto (1891 a 1894) e de Prudente de Moraes (1894 a 1898), a anarquia dominava a administração, especialmente as finanças: "o país empobrecia-se e desmoralizava-se". A partir de 1894, após eleições presidenciais, o país passou a viver sob domínio formal das elites civis. O legado dos governos militares deixou em aberto as mesmas questões suscitadas quando da época do Império: quem faz parte da comunidade política? Como serão as relações entre pólis e demos? Entre Poder Central e estados? Como se organizarão os partidos? (Lessa, 1999).

De acordo com Guanabara (2002:25) o governo Prudente de Moraes, eleito em 1894, novamente sofreu com a não determinação de regras para a constituição da pólis:

A anarquia que reinava na administração pública, desde as primeiras agitações políticas que determinaram a retirada do Governo Provisório que proclamou a República (...) não fez senão agravar-se durante os quatro anos do período presidencial do Sr. Prudente de Moraes.

Entretanto, devido às ameaças externas como a Revolta da Armada, o revanchismo monárquico e a revolta separatista gaúcha, gerou-se uma harmonia momentânea entre o Executivo e o Legislativo, ao mesmo tempo que Floriano Peixoto se aproximou das elites civis. A eleição de Prudente de Moraes foi viabilizada pelo primeiro partido político de caráter nacional criado após a dissolução dos partidos monárquicos em 1893. O Partido Republicano Federal (PRF) apoiava o governo e controlava as bancadas estaduais no Congresso, mas estava longe de ser uma unidade ideológica. A partir de 1895 três facções agiam em conflito: os radicais fanáticos de Floriano, os reacionários inimigos dos jacobinos e os moderados. De fato, o maior problema do novo governo foi lidar com o partido que o elegera e, por extensão, com o Legislativo (Lessa, 1999).

Dentre as ações do Executivo, destaca-se o afastamento dos militares da cena política por meio da exoneração de oficiais em cargos civis e de funcionários florinianistas, por meio do veto do aumento dos efetivos militares e pela cooptação de oficiais graduados (premiandoos com promoções conforme se abstinham da política). Essas medidas provocaram reação da plebe nas ruas da capital. Lessa (1999:112) observa que nas ruas "odiavam-se os portugueses, os políticos em geral e os monarquistas em particular, protestava-se contra a alta dos aluguéis e do custo dos alimentos e, sobretudo, cultuava-se Floriano". A tensão entre militares e civis continua e a imprensa oposicionista aparece. Ao mesmo tempo, o núcleo do PRF age contra o governo utilizando-se do orçamento. Em meio a todo esse caos, a crise financeira se agrava devido à dívida herdada dos militares e à baixa no preço do café. Em 1897, Prudente de Moraes em bela manobra política causa a ruptura do PRF, solicitando apoio de estados como SP, MG, BA e PE. Em novembro daquele ano, a oposição atenta contra a vida do presidente, que consegue sobreviver. É declarado o estado de sítio e vários são indiciados pelo atentado, inclusive deputados e senadores. A oposição ou foi presa ou se aliou ao governo que só agora começava a funcionar. Sem bloqueios de oposicionistas e com os militares colocados às margens da cena política e humilhados pelas seguidas derrotas em Canudos, um contexto favorável ao Executivo é percebido (Lessa, 1999). 
Para Prudente de Moraes, a estabilidade do novo regime dependeria da existência de um pacto político instrumentalizado pela administração pública que fosse capaz de regular ao mesmo tempo as relações entre o Executivo e o Legislativo. Dependeria também do estabelecimento dos atores políticos e da relação entre o poder central e os poderes regionais. A ideia era a de que o Legislativo deveria ter a fonte de seu poder nos estados e que a lealdade parlamentar dependeria de acordos com os chefes estaduais. Para ele, a administração pública seria importante instrumento à concretização da ideia do pacto, tarefa esta que coube a Campos Sales, já como candidato à sua sucessão (Lessa, 1999).

\section{Procedimentos e valores republicanos}

Para Campos Sales, respaldado pelo programa do Partido Republicano Paulista (Penna, 2008), o governo teria a função de administrar. A administração deveria ficar separada da política e esta deveria ficar restrita aos estados sob responsabilidade dos chefes locais. Em termos pragmáticos, o programa reforçava o Poder Executivo, enfatizando o governo unipessoal sob a figura do presidente, com controle sobre o Executivo e demarcando rigidamente as atribuições do Legislativo.

Outro ponto a destacar diz respeito à questão financeira. Havia o resgate do papelmoeda e a moralização da arrecadação nos moldes de um plano conservador de saneamento monetário, bem como a definição de uma política para os serviços públicos ajustada à política macroeconômica (Franco, 1992).

Quanto à questão da estabilização do sistema federativo, o programa revelava a intenção de Campos Sales de organizar as relações entre pólis e governo, delimitando suas áreas de competência e influência mútua, onde seriam previsíveis os critérios do acesso da pólis ao governo. A autonomia dos estados visava, sobretudo, garantir a autonomia do Executivo federal. A intenção era redimensionar o espaço público de modo a atribuir aos estados o tratamento do que Campos Sales entendia ser as mazelas da política, os vícios e interesses privados, deixando o presidente livre para governar. Portanto, o espaço para a política seriam os estados e é lá que o demos deveria ser controlado (Guanabara, 2002).

De modo geral, a proposta era fortalecer os seguintes elementos: o presidencialismo identificando o presidente como aquele que administra e governa, o federalismo com máxima autonomia aos estados, a defesa da administração pública moderna e técnica e um programa de austeridade financeira. $\mathrm{O}$ discurso a ela associado expressava o esvaziamento dos meios como eminentemente neutros e racionais em busca de eficiência e isentos de paixões políticas. Ao mesmo tempo que procurava dotar a administração do governo de uma unidade política em nome de uma governabilidade, buscava excluir o Legislativo das atividades relacionadas à administração. Logo, por reconhecer que a administração deve ser separada da política, das ditas paixões políticas e lidar com ambas em seu arranjo de poder, o modelo proposto pautou-se em racionalidades distintas, denominadas técnica e não técnica. Assim, fez-se uso 
das interações políticas tradicionais e, ao mesmo tempo, procurou-se insular seu espaço de atuação, isolando, simbolicamente, a política da administração.

Por associar diferentes racionalidades, a Política dos Estados, como resposta a problemas práticos da política, pode ser vista, conforme Lessa (1999:28), sob dois aspectos complementares: o que se refere a procedimentos circunstanciais e o que diz respeito a valores substantivos perenes:

O primeiro é composto por um conjunto de procedimentos postos em ação para obter estabilidade e dotar a República de um padrão mínimo de governabilidade. Eles se resumem à montagem da política dos governadores e à operação da Comissão de Verificação de Poderes. O segundo aspecto diz respeito aos valores que Campos Sales atribuiu ao seu modelo, notadamente uma concepção despolitizadora e administrativa do governo, dotado da atribuição de resguardar o interesse nacional.

Tem-se, segundo a interpretação de Lessa (1999), que procedimentos não podem ser considerados à parte dos valores que os orientam, pois procedimentos expressam determinado teor republicano. Como pólis e demos surgem descolado um do outro na Política dos Estados, tem-se que, num contexto republicano, a condição que em tese deveria impedir o uso arbitrário do poder e a posse privada dos meios de poder, o demos está ausente.

Concluindo, é possível afirmar que o pacto objetivou estabelecer a rotinização da República redefinindo o lugar e os limites do Congresso e do presidencialismo unitário. A estabilidade derivou de um arranjo informal entre o poder central e os poderes locais considerando a distribuição regional de poder preexistente ao mesmo tempo que fortalecia o governo unipessoal. É possível resumir o arranjo do seguinte modo: "os estados são autônomos, o Parlamento é digno e fundamental, mas quem manda é o Presidente" (Lessa, 1999:142).

Nesse contexto, o controle sobre a representação no Congresso Nacional é crucial para o cumprimento das diretrizes da Política dos Estados, conforme destacam Souza (1981), Cardoso (1975) e Debes (1977). Campos Sales estabelece, então, por meio da Comissão de Verificação de Poder, uma política de acordos com os chefes estaduais que passaram a controlar o acesso ao Legislativo e que, ao mesmo tempo, se garantiam no poder adquirindo condições de eternização nos governos dos estados. "Mandato legítimo é todo aquele que tem por origem a política oficial de seu estado" (Lessa, 1999:148). Com esse modelo, segundo Souza (1981:185), "resolve-se assim os problemas partidários mais importantes da atividade política, aqueles relacionados à formação das estruturas de dominação nos Estados...”. Resolve-se, também, segundo Santos (1998), o programa de saneamento financeiro.

Portanto, graças à engenharia política do pacto com as oligarquias estaduais e a definição do governo como instrumento de administração, a República encontrou a sua rotina (Lessa, 1999). Os anos entrópicos da República foram superados. Como resultado, tem-se o controle do Executivo sobre a dinâmica legislativa, as eleições, as administrações regionais, a administração federal e sobre o processo de geração de atores políticos legítimos, além da política fiscal e monetária. Vê-se que o programa do PRP já anunciava os principais valores que 
norteariam a Política dos Estados. Contudo, cabe considerar também a experiência prática dos procedimentos, assim como seus princípios, que, entende-se, expressavam determinada visão de ordem pública, ordem republicana, que caberia à administração pública instrumentalizar. De fato, os valores do pacto determinaram a execução de seus procedimentos. Havia então uma coerência entre o discurso e as ações políticas, desde o momento em que Campos Sales, como candidato, tornou público o seu manifesto até o instante em que se elegeu presidente, articulando a execução do modelo conhecido como "Política dos Estados".

\section{0 modelo de mudança institucional gradual e transformativa}

Ao estudar o novo institucionalismo histórico, Hall e Taylor (1996) argumentam que o comportamento coletivo é estruturado pela organização institucional da comunidade política, não pelas características sociais, psicológicas ou culturais dos indivíduos. Dessa forma, o Estado não é mais um agente neutro que arbitra interesses divergentes, mas sim um complexo de instituições que estrutura os conflitos entre grupos (Hall e Taylor, 1996). A partir daí, questionase como as instituições podem afetar o comportamento dos indivíduos e como os indivíduos podem influenciá-las. Os neoinstitucionalistas históricos fornecem dois tipos de resposta para essa questão, levando em consideração a maneira como os atores se comportam, o que fazem as instituições e por que elas se mantêm. O primeiro enfoque é chamado "perspectiva calculadora" e o segundo, "perspectiva cultural".

De acordo com a perspectiva calculadora, a análise do comportamento dos indivíduos dá ênfase aos aspectos instrumentais e ao cálculo estratégico. Os atores examinam todas as escolhas possíveis para selecionar aquelas que oferecem um benefício máximo. Desse modo, as instituições oferecem uma certeza relativa quanto ao comportamento presente e futuro dos demais atores, ou seja, incidem sobre expectativas de um ator no tocante às ações que os outros são suscetíveis de realizar em reação às suas próprias ações. Por outro lado, segundo a perspectiva cultural, o comportamento não é puramente estratégico, mas limitado pela visão de mundo do indivíduo. Embora racional e orientado para fins, frequentemente o indivíduo recorre a modelos de comportamento já conhecidos para atingir seus objetivos. Logo, uma ação dependeria mais da interpretação de uma situação do que de um cálculo utilitário. As instituições fornecem então modelos morais e cognitivos que viabilizam a interpretação e a ação (Hall e Taylor, 1996).

Segundo a perspectiva cultural do novo institucionalismo histórico, o indivíduo está inserido em um mundo de instituições constituídas de símbolos, cenários e protocolos que filtram o processo de interpretação, afetando a constituição da identidade e das preferências que guiam as ações. Peci, Vieira e Clegg (2006:59) argumentam ainda que:

As instituições regulam a imagem da realidade para os sujeitos que atuam e participam de certa sociedade. Essas interpretações geradas tipificam atores e ações e circulam como saber comum de todos os sujeitos que participam dessa sociedade. É um senso de realidade que define os lu- 
gares e sentidos da relação identidade/mundo; são códigos de signos com os quais se conhece a realidade.

Nota-se que tais abordagens tratam as instituições como duradouras, tendendo ao equilíbrio e com pouca propensão a mudança. As perspectivas se direcionam à continuidade das instituições e para como elas se reproduzem ao guiar as decisões e ações humanas. Streeck e Thelen (2005:1) resumem a forma como o tema é comumente abordado no institucionalismo:

Muito da literatura institucional acredita - explícita ou implicitamente - em um modelo de equilíbrio pontual que aponta uma distinção bem definida entre longos períodos sem mudança periodicamente interrompidos por algum choque externo que transforma o contexto, propiciando uma reorganização mais ou menos radical.

Observando o quadro 1, Thelen (2009:476) pondera que na análise institucional muita atenção é dada ao primeiro quadrante: "o problema é que a literatura tende a priorizar a estabilidade, ou, em alguns casos, caracterizar quaisquer mudanças observadas como ajustes menores em um padrão mais amplo de reprodução do modelo".

Por outro lado, argumenta-se que as instituições estão em constante transformação, ou seja, a mudança pode ocorrer tanto por meio de eventos exógenos quanto pela ação cotidiana dos indivíduos — através de rupturas e de modo incremental (Thelen, 2009). Mahoney e Thelen (2010) reforçam que a mudança institucional, embora sujeita a rupturas, possui em regra um caráter transformativo e incremental. A mudança é contínua, lenta e gradual.

Quadro 1

Tipos de mudança institucional: processos e resultados

\begin{tabular}{|c|c|c|c|}
\cline { 3 - 3 } \multicolumn{2}{c|}{} & \multicolumn{2}{c|}{ Resultado da mudança } \\
\cline { 3 - 4 } Processo de mudança & Incremental & Reprodução por adaptação & Transformação gradual \\
\cline { 2 - 4 } & Abrupta & Sobrevivência e & Ruptura e \\
& retorno & substituição \\
\hline
\end{tabular}

Fonte: Streeck e Thelen (2005).

Bell (2011) argumenta que as abordagens que compõem o novo institucionalismo adotaram uma visão determinística em relação aos limites impostos pelas instituições, resultando em uma análise bastante restritiva em relação à agência. Disso percebe-se uma dificuldade em se explicar como mudam as instituições. Logo, o poder ou o direito do indivíduo decidir ou agir segundo seu próprio julgamento ou escolha (discretion) é de certa forma negligenciado.

Entretanto, a partir da perspectiva cultural e da ideia de que os indivíduos interpretam as instituições, assim como de acordo com a perspectiva calculadora que apresenta o indiví- 
duo buscando a realização de seus objetivos por meio da ação racional, é possível considerar que os atores também confrontam as instituições (Bell, 2011).

Ora, o engajamento dos atores faz com que a própria interpretação possa provocar mudança na forma como a instituição é aplicada, conforme descrevem Streeck e Thelen (2005), Thelen (2009) e Mahoney e Thelen (2010). Analisando então o processo de mudança institucional, levam em consideração as seguintes premissas:

จ O sistema é composto por múltiplos atores com interesses diversos e desigual distribuição de poder;

、 Os atores interpretam as instituições de maneiras diferentes;

、 As preferências e interesses de cada ator podem ser ambíguos;

v A agência provoca também consequências não premeditadas;

v Os atores permeiam múltiplos ambientes institucionais complexos.

Assim, Mahoney e Thelen (2010) argumentam que as instituições atuam como instrumentos distributivos de recursos com implicações de poder, de modo que os arranjos institucionais passam a refletir os interesses de coalizões. Há uma perspectiva dinâmica, em que mesmo a continuidade depende de mobilização constante de suporte político e do esforço ativo para resolver ambiguidades institucionais. A ambiguidade de interesses e interpretações, bem como o equilíbrio de poder e a obediência às instituições criam espaços para a mudança institucional. Mahoney e Thelen (2010:14) acrescentam ainda: "espera-se a mudança incremental emergir nos gaps entre a regra e sua interpretação ou entre a regra e a sua aplicação". Nesse hiato, as manifestações das coalizões podem propiciar a mudança necessária para que haja um rearranjo institucional que melhor acomode a distribuição de recursos.

Bell (2011) defende um enfoque no novo institucionalismo histórico que não prioriza a agência, instituições, estruturas ou ideias, mas que considera cada elemento como mutuamente constitutivo de maneira dialética. Para ele, as instituições são confrontadas como um extrato da realidade, isto é, são entidades com as quais é preciso lidar no presente, mas que podem mudar com o passar do tempo. Aliás, a análise social de uma atividade corrente deve levar em consideração condições antecedentes. Nota-se uma relação dialética entre agentes e estruturas ao longo do tempo: as interações ciclicamente repetidas geram propriedades emergentes, diferentes das originais.

Considerando que agentes e ambientes interagem e se moldam mutuamente ao longo do tempo, percebe-se que as instituições podem limitar o comportamento, mas também são resultado (consciente ou imprevisto) de estratégias deliberadas. Bell (2011) parece convergir com Schmidt (2008) quando reconhece na relação dialética entre ideias e contexto que os agentes interpretam e constroem experiências a partir de sua situação institucional através de modelos subjetivos e intersubjetivos, cognitivos e normativos em processos de discurso. Além disso, outra capacidade observada nos agentes que pode provocar mudança diz respeito aos graus de liberdade de escolha (degrees of discretion, segundo Mahoney e Thelen, 2010) 
quando agentes interpretam sua situação e avaliam seus recursos e capacidades diante das instituições. Dessa forma, a dinâmica institucional envolve lutas de poder a partir do momento em que os atores exploram suas posições institucionais e empregam recursos para vencer batalhas e remodelar os ambientes institucionais.

Continuando com a descrição de seu modelo, Mahoney e Thelen (2010) propõem que as mudanças são determinadas pelas características do contexto político (possibilidade de veto), pelas características da própria instituição (interpretação e sua aplicação) e pelo tipo de agente da mudança dominante. Considerando o comportamento desses elementos, quatro tipos de mudança seriam possíveis: por substituição, por camadas, por deslocamento e por conversão. O quadro 2 apresenta de maneira sucinta as características de cada tipo de mudança institucional.

Quadro 2

Estratégias de mudança institucional segundo Mahoney e Thelen (2010)

\begin{tabular}{|c|c|c|c|}
\hline Substituição & Camadas & Deslocamento & Conversão \\
\hline $\begin{array}{l}\text { Vemoção de regras } \\
\text { existentes e introdução de } \\
\text { novas. Há um período em } \\
\text { que elas competem. } \\
\text { v Atores "perdedores" } \\
\text { em antigas instituições } \\
\text { introduzem as novas regras. } \\
\text { Se não há resistência, a } \\
\text { mudança ocorre. }\end{array}$ & $\begin{array}{l}\text { Vovas regras (ou emendas } \\
\text { e revisões) são adicionadas } \\
\text { às antigas, mudando o } \\
\text { impacto das regras originais } \\
\text { no comportamento dos } \\
\text { indivíduos. } \\
\text { จ Os "perdedores" não } \\
\text { conseguem introduzir uma } \\
\text { nova instituição. }\end{array}$ & $\begin{array}{l}\text { As regras continuam as } \\
\text { mesmas, mas seu impacto } \\
\text { muda devido a alterações } \\
\text { no contexto. } \\
\text { vegligência em aceitar as } \\
\text { mudanças de contexto: } \\
\text { falha em adaptar a regra } \\
\text { para que esta mantenha o } \\
\text { impacto em um ambiente } \\
\text { que muda. }\end{array}$ & $\begin{array}{l}\text { V As regras continuam } \\
\text { formalmente as mesmas, } \\
\text { mas são interpretadas } \\
\text { e aplicadas de outras } \\
\text { maneiras. } \\
\text { v Há uma exploração } \\
\text { do espaço criado pela } \\
\text { ambiguidade. }\end{array}$ \\
\hline
\end{tabular}

Fonte: Elaboração do autor.

Uma vez descritos os tipos de mudanças institucionais, é preciso descrever os tipos de atores envolvidos nesses processos. Afinal, quem são os agentes de mudança da estrutura? Mahoney e Thelen (2010) estabelecem a seguinte tipologia: insurgentes, simbióticos, subversivos e oportunistas. Os primeiros rejeitam o status quo, tentam alterar a instituição e nem sempre obedecem as regras. Os simbióticos se dividem em dois subtipos: os parasitas que exploram a instituição para ganhos próprios, minando-a no longo prazo, e os mutualísticos que agem da mesma forma, porém sem comprometer a sobrevivência da instituição. Já os subversivos não agem diretamente para provocar a mudança. Parecem dar suporte à instituição, mas agem esperando o momento certo para assumirem a condição de opositores. Eles propõem novas regras sem extinguir as antigas. Finalmente, observam-se os oportunistas. Estes possuem preferências ambíguas a respeito da continuidade da instituição e não procuram ativamente preservá-la, mas, dados os custos, também não se engajam em alterá-la. Exploram as possibilidades do sistema para atingirem seus fins, mas, quando agem por mudança, adotam a estratégia do tipo conversão. 
Logo, pode-se relacionar os tipos de mudanças com os tipos de agentes de transformação da estrutura. Mahoney e Thelen (2010) estabelecem a seguinte relação. Os insurgentes buscam mudanças rápidas, mas aceitam substituição gradual; os simbióticos procuram preservar o status quo, mas sua atuação parasita gera deslocamento; os subversivos buscam a substituição, mas trabalham no curto prazo usando a estratégia do tipo camadas; os oportunistas aguardam, mas quando agem, buscam a conversão.

\section{Conclusão}

O quadro 3 apresenta de forma resumida o contexto institucional que marcou o país desde os últimos dias da Monarquia até a rotinização da República no governo Campos Sales, num horizonte de 13 anos. Verifica-se um contexto ambíguo, em que as instituições se mostravam fragilizadas e sujeitas à interferência da agência a partir do jogo político dos diversos atores. Nesse período, destaca-se a postura ativa das elites civis republicanas que agiram em prol da mudança de regime político e depois se mantiveram engajadas em busca de sua consolidação.

Quadro 3

\section{Contexto institucional e ações políticas entre a Monarquia e o governo Campos Sales}

\begin{tabular}{|c|c|}
\hline Período & Contexto Institucional \\
\hline Monarquia & 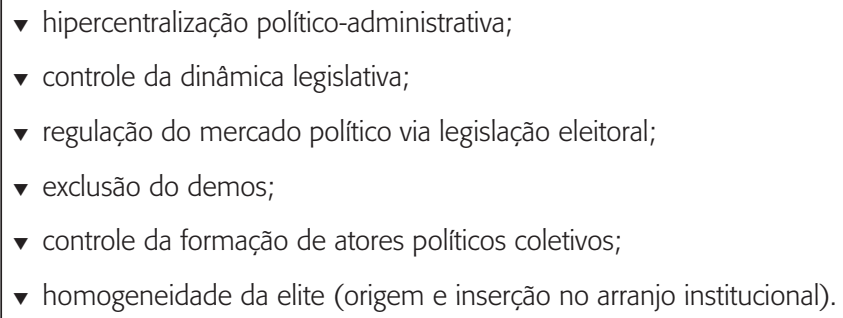 \\
\hline $\begin{array}{l}\text { Proclamação da República } \\
\text { (1889) }\end{array}$ & 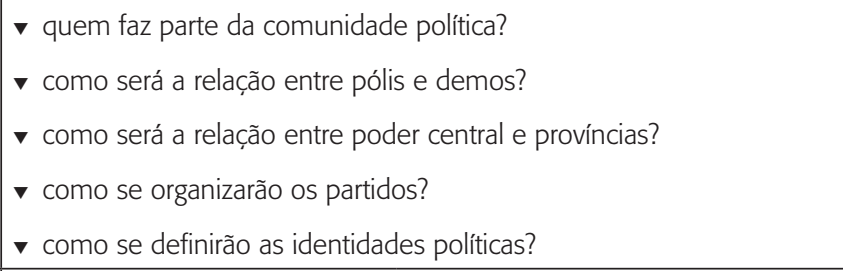 \\
\hline $\begin{array}{l}\text { Anos Entrópicos (1889- } \\
98)\end{array}$ & 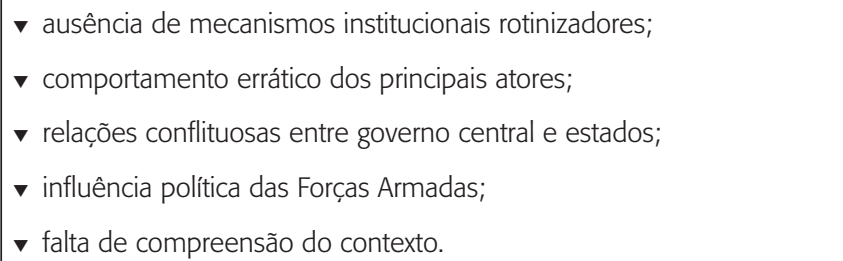 \\
\hline
\end{tabular}




\begin{tabular}{|c|c|}
\hline Período & Contexto Institucional \\
\hline $\begin{array}{l}\text { Assembleia Constituinte } \\
\text { (1890) }\end{array}$ & 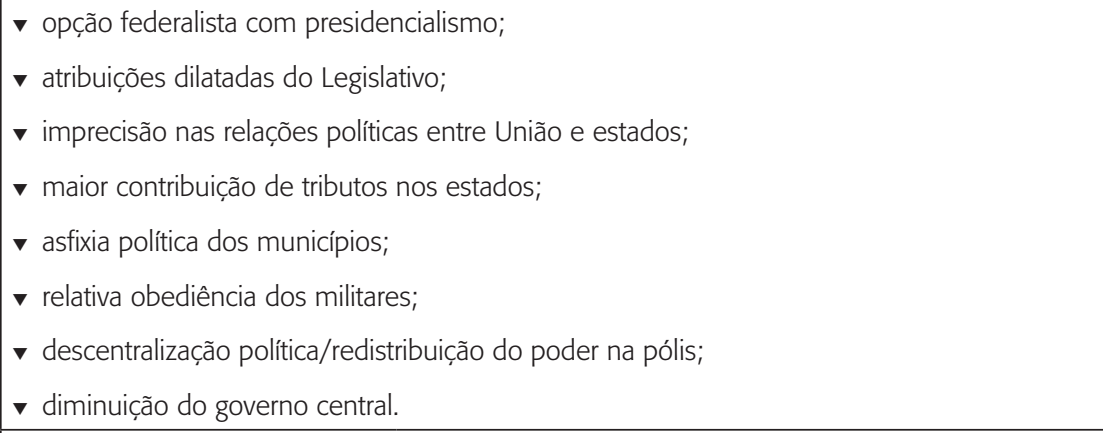 \\
\hline $\begin{array}{l}\text { Governo Floriano Peixoto } \\
(1891-94)\end{array}$ & 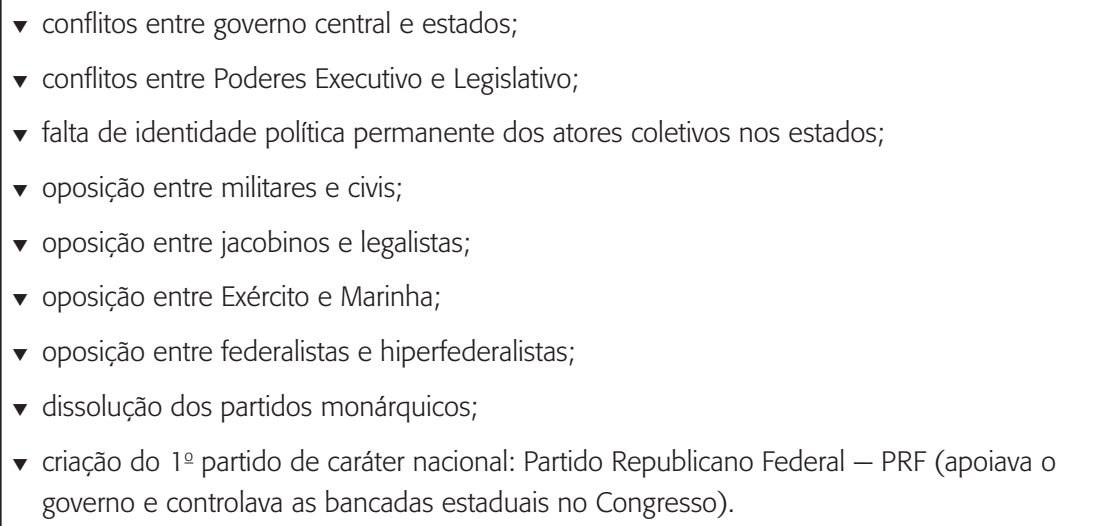 \\
\hline $\begin{array}{l}\text { Governo Prudente de } \\
\text { Moraes (1894-98) }\end{array}$ & 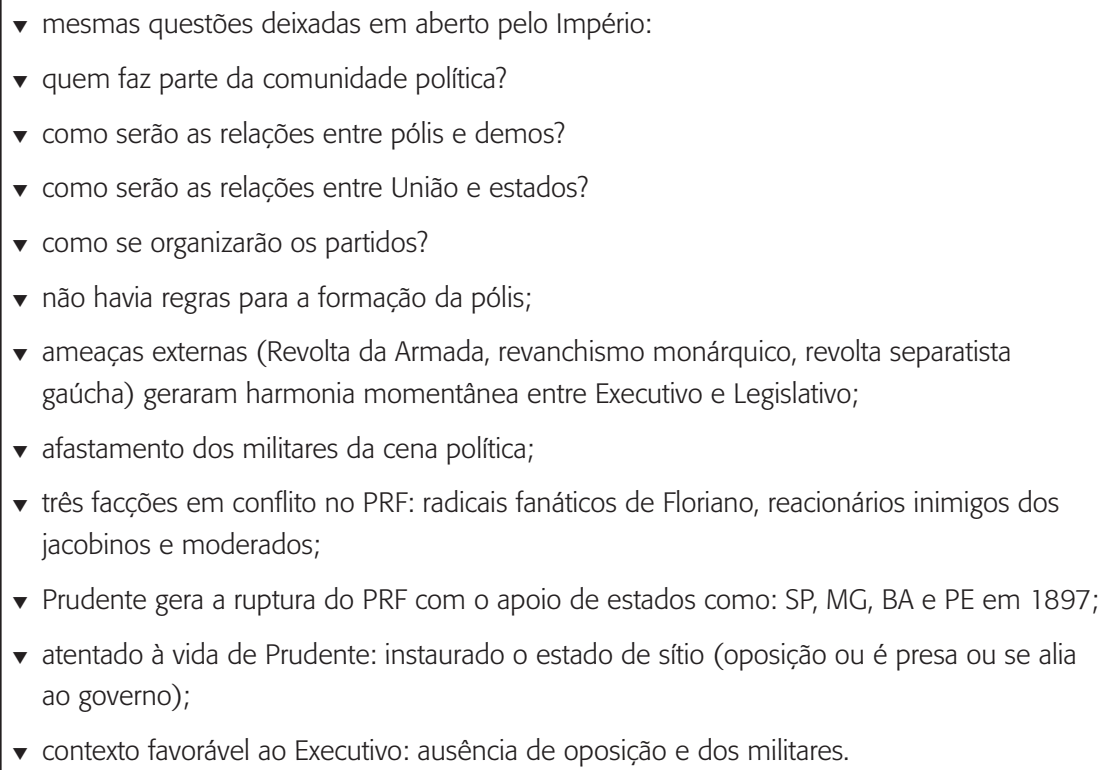 \\
\hline
\end{tabular}

Continua 


\begin{tabular}{|c|c|c|}
\hline Período & \multicolumn{2}{|l|}{ Contexto Institucional } \\
\hline $\begin{array}{l}\text { Governo Campos Sales } \\
(1898-1902)\end{array}$ & \multicolumn{2}{|c|}{ 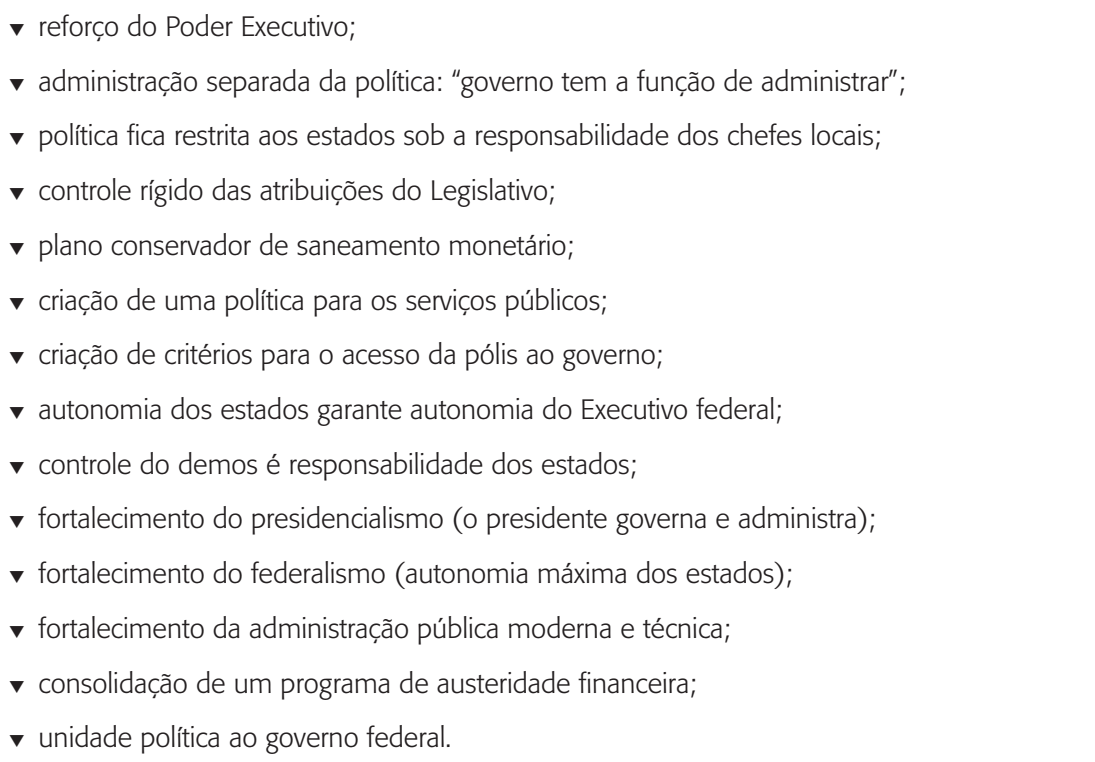 } \\
\hline \multicolumn{3}{|c|}{$\begin{array}{l}\text { Política dos Estados de Campos Sales: o meio para a rotinização da República } \\
\text { O modelo adota duas racionalidades: técnica e não técnica. Fez uso das interações políticas tradicionais, mas restringiu seu } \\
\text { espaço de atuação isolando a política da administração. Em um contexto republicano, há o uso arbitrário do poder e a posse } \\
\text { privada dos meios de poder com a exclusão do demos. } \\
\text { A estabilidade deriva de um arranjo informal entre o poder central e os poderes locais. Por meio da Comissão de Verificação } \\
\text { de Poder é estabelecida uma política de acordos com os chefes estaduais que passam a controlar o acesso ao Legislativo e } \\
\text { se garantem perpetuamente no poder. }\end{array}$} \\
\hline \multicolumn{2}{|c|}{$\begin{array}{l}\text { Procedimentos circunstanciais: } \\
\text { v proporcionar estabilidade e governabilidade à República } \\
\text { por meio da montagem da Política dos Governadores } \\
\text { (ou Política dos Estados) e operação da Comissão de } \\
\text { Verificação de Poderes. }\end{array}$} & $\begin{array}{l}\text { Valores substantivos perenes: } \\
\text { v valores atribuídos por Campos Sales ao seu modelo: } \\
\text { concepção despolitizadora e administrativa do governo e } \\
\text { o resguardo do interesse nacional. }\end{array}$ \\
\hline
\end{tabular}

Fonte: Elaboração do autor.

As elites civis tentaram a todo custo fortalecer o Poder Executivo e controlar o Poder Legislativo, afastando de vez a influência dos militares (algo que de fato só ocorreu em 1894, com a eleição de Prudente de Moraes). Não obstante, lograram êxito em dominar a formação de novos atores e seu acesso à arena política. A leitura que se faz é a de que as elites civis, mesmo com eventuais discordâncias ou rachas, compuseram nesse período uma coalizão capaz de transformar as instituições através da remoção de regras antigas e introdução de outras novas, não apenas num processo simples de pura substituição mas também através da revisão e adoção de emendas e das normas já estabelecidas. 
Nesse sentido, mesmo após a Assembleia Constituinte, algumas características da Monarquia permaneceram, pois serviam ao propósito de quem agora exercia o poder: centralização da administração, exclusão do demos e regulação do mercado político. A Política dos Estados, instituída por Campos Sales, utilizou-se da Comissão de Verificação de Poder e da conveniente autonomia das elites regionais para assegurar essa condição. Logo, com um contexto institucional estável, foi possível desenvolver a organização da administração pública e a institucionalização da República.

Analisando o caso sob a ótica do modelo de mudança institucional gradual e transformativa de Thelen e colegas, conclui-se que, na transição do Império para a República, houve uma mudança do tipo substituição. Ou seja, houve remoção de regras existentes e introdução de outras novas - instauração da Assembleia Constituinte de 1890. As elites civis republicanas, "perdedoras" no antigo contexto institucional, comportaram-se como insurgentes comprometidos com a mudança gradual.

Por outro lado, uma série de ações foi praticada de modo a completar o processo de mudança institucional. A coalizão antes "perdedora" agora se vê no poder e então implementa um processo de mudança gradual do tipo por camadas já que novas regras são adicionadas às antigas, mudando o impacto das regras originais no comportamento dos indivíduos - a operação da Comissão de Verificação de Poderes. Aqui, ressalta-se uma proposição de Mahoney e Thelen (2010): mesmo a continuidade depende de mobilização constante de suporte político e do esforço ativo para resolver ambiguidades institucionais. A favor da manutenção do status quo, os atores prolongam sua interferência no processo de mudança institucional.

Uma leitura mais apurada a respeito da conduta das elites republicanas civis demonstra uma estratégia condizente com a postura de subversivos. Afinal, mantiveram-se fiéis aos militares republicanos durante a Proclamação da República, mas, em seguida, gradativamente foram tornando explícita sua oposição à influência militar até que em 1894 elegeram Prudente de Moraes. A partir de então, conforme já demonstrado, os militares foram plenamente afastados do poder. O papel de subversivos converge com a ideia de introdução paulatina de um novo arranjo institucional que culminou com a legitimação da Política dos Estados.

Por fim, após analisar o processo de mudança institucional gradual e transformativa que levou à consolidação da República no Brasil, cabem algumas questões que podem subsidiar futuras pesquisas e reflexões sobre o tema: como se daria o contraponto à abordagem dada a este caso a partir do enfoque do modelo de equilíbrio pontuado de mudança? Quais seriam os fatores exógenos que poderiam explicar a rotinização da República no país? A partir da instauração da Política dos Estados, como se comportaram as elites civis nos anos seguintes, isto é, que postura e que tipos de estratégias adotaram em seu esforço para manter o status quo favorável? 


\section{Referências}

BALÁN, Jorge; CINTRA, Antônio O. Centro e periferia no desenvolvimento brasileiro. Difusão Europeia do Livro, 1974.

BELL, Stephen. Do We really need a new 'constructivist institucionalism' to explain institutional change? British Journal of Political Science, v. 41, n. 1, p. 1-24, 2011.

CARDOSO, Fernando H. Dos governos militares a Prudente - Campos Sales. In: FAUSTO, Boris (Dir.). O Brasil republicano. São Paulo: Difel, 1975. v. 3. Estrutura do poder e economia. (História geral da civilização brasileira, v. 8).

CARVALHO, José M. de. A construção da ordem: a elite política imperial. Rio de Janeiro: Civilização Brasileira, 2003.

CARVALHO, José. M. de. A formação das almas: o imaginário da República no Brasil. São Paulo: Companhia das Letras, 1990.

CARVALHO, José M. de (Org.). Ensaio sobre o direito administrativo. Visconde de Uruguai. São Paulo: Ed.34, 2002.

CARVALHO, José M. de. Os bestializados: o Rio de Janeiro e a República que não foi. São Paulo: Companhia das Letras, 1987.

CARVALHO, José M. de. Pontos e bordados: escritos de história e política. 2. reimp. Belo Horizonte: UFMG, 2005.

DEBES, Célio. Campos Salles — perfil de um estadista. São Paulo: Instituto Histórico e Geográfico de São Paulo, 1977.

FALLETI, Tulia G. Infiltrating the State: the evolution of health care reforms in Brazil, 1964-1988. In: MAHONEY, James; THELEN, Kathleen. Explaining institutional change: ambiguity, agency and power. Cambridge: Cambridge University Press, 2010. p. 38-62.

FILGUEIRAS, Fernando. República, Confiança e sociedade. Dados, Rio de Janeiro, v. 50, n. 4, p. 863-897, 2007.

FISCHER, Tânia. Alice através do espelho ou Macunaíma em campus papagali? Mapeando rotas de ensino dos estudos organizacionais no Brasil. Organizações \& Sociedade, Salvador, v. 10, n. 28, p. 46-63, 2003.

FRANCO, Gustavo. A primeira década republicana. In: ABREU, Marcelo de P. (Org.). A ordem do progresso: cem anos de política econômica republicana, 1889-1989. Rio de Janeiro: Campus Editora, 1992. p. 11-30.

GUANABARA, Alcindo. A presidência Campos Sales. Brasília: Senado Federal, 2002.

HALL, Peter A.; TAYLOR, Rosemary C. A. Political science and the three new institucionalisms. Political studies, v. 44, n. 5, p. 936-957, 1996. 
HEMAIS, Bárbara J. W.; VERGARA, Sylvia C. A cultura anglo-americana na produção brasileira: um estudo de intertextualidade de trabalhos em estudos organizacionais. In: ENCONTRO DA ANPAD, 24., 2000, Florianópolis. Anais... Rio de Janeiro: ANPAD, 2000. p. 1-12.

HEMAIS, Bárbara J. W.; VERGARA, Sylvia C. O jeito brasileiro de publicar em estudos organizacionais. Organizações \& Sociedade, Salvador, v. 8, n. 20, p. 45-54, jan./abr. 2001.

LAFER, Celso. O significado de República. Estudos Históricos, Rio de Janeiro, v. 2, n. 4, p. 214-224, 1989.

LESSA, Renato. A invenção da República: da aventura à rotina. In: CARVALHO, Maria A. R. (Org.). A República no Catete. Rio de Janeiro: Museu da República, 2001. p. 11- 58.

LESSA, Renato. A invenção republicana. Rio de Janeiro: Topbooks, 1999.

MAHONEY, James; THELEN, Kathleen. A theory of gradual institutional change. In: MAHONEY, James; THELEN, Kathleen. Explaining institutional change: ambiguity, agency and power. Cambridge: Cambridge University Press, 2010. cap. 1.

MISOCZKY, Maria C. Uma defesa da reflexão teórico-crítica na pesquisa e prática da administração pública. In: ENCONTRO DE ADMINISTRAÇÃO PÚBLICA E GOVERNANÇA, 1., 2004, Rio de Janeiro. Anais... Rio de Janeiro: ANPAD, 2004. p. 1-14. CD-ROM.

MOTTA, Fernando C. P.; ALCADIPANI, Rafael; BRESLER, Ricardo. B. A valorização do estrangeiro como segregação nas organizações. Revista de Administração Contemporânea, v. 5, n. Edição Especial, p. 59-79, dez. 2001.

NUNES, Edson. A gramática política do Brasil: clientelismo e insulamento burocrático. 3. ed. Rio de Janeiro: Jorge Zahar; Brasília, DF: Enap, 2003.

PECI, Alketa; VIEIRA, Marcelo M. F.; CLEGG, Stewart R. A construção do real e práticas discursivas: o poder nos processos de institucionaliz(ação). Revista de Administração Contemporânea, v. 10, n. 3, p. 51-71, 2006.

PENNA, Lincol. Manifestos políticos do Brasil contemporâneo. Rio de Janeiro: E-papers, 2008.

RODRIGUES, Suzana B.; CARRIERI, Alexandre P. A tradição anglo-saxônica nos Estudos organizacionais. Revista de Administração Contemporânea, v. 5, n. Edição Especial, p. 81-102, dez. 2001.

SANTOS, Wanderley G. Décadas de espanto e uma apologia democrática. Rio de Janeiro: Rocco, 1998.

SCHMIDT, Vivien A. Discursive institucionalism: the explanatory power of ideas and discourse. Annual Review of Political Science, v. 11, p. 303-326, 2008.

SCOTT, W. Richard. Institutions and organizations. Thousand Oaks: Sage, 1995.

SOUZA, Maria C. C. O processo político-partidário na Primeira República. In: MOTA, Carlos Guilherme. Brasil em perspectiva. 12. ed, São Paulo; Rio de Janeiro: Difel, 1981.

STREECK, Wolfgang; THELEN, Kathleen. Beyond continuity: institutional change and advanced political economies. Nova York: Oxford University Press, 2005. 
THELEN, Kathleen. Institutional change in advanced political economies. British Journal of Industrial Relations, v. 47, n. 3, p. 471-498, 2009.

THOENIG, Jean-Claude. Recuperando a ênfase na dimensão pública dos estudos organizacionais. Rev. Adm. Pública, Rio de Janeiro, v. 41, n. esp., p. 9-36, 2007. Disponível em: <www.scielo.br/ scielo.php? script $=$ sci_arttext\&pid $=$ S003476122007000700002\&lng $=$ pt\&nrm $=$ iso $>$. Acesso em: 5 abr. 2010.

URICOECHEA, Fernando. O minotauro imperial: a burocratização do estado patrimonial brasileiro no século XIX. Rio de Janeiro: Difel, 1978.

VERGARA, Sylvia C. A hegemonia americana em estudos organizacionais. Rev. Adm. Pública, Rio de Janeiro, v. 35, n. 2, p. 63-77, mar./abr. 2001.

VERGARA, Sylvia; CARVALHO JÚNIOR, D. S. Nacionalidade dos autores referenciados na literatura brasileira sobre organizações. Revista Brasileira de Administração Contemporânea, Rio de Janeiro, v. 1, n. 6, p. 170-188, 1995.

VERGARA, Sylvia; PINTO, Mário C. S. Referências teóricas em análise organizacional: um estudo das nacionalidades dos autores referenciados na literatura brasileira. Revista de Administração Contemporânea, Rio de Janeiro, v. 5, n. Edição Especial, p. 103-121, 2001.

VIANNA, Luiz W. O Estado-Novo e a "ampliação" autoritária da República. In: CARVALHO, Maria Alice R. (Org.). A República no Catete. Rio de Janeiro: Museu da República, 2001. p. 111-153.

Diego Mota Vieira é doutor em administração e professor adjunto do Departamento de Administração da UnB. E-mail: diego1mv@unb.br.

Leonor Moreira Câmara é doutora em administração e professora adjunta do Departamento de Administração da UnB. E-mail: leonor@unb.br.

Ricardo Corrêa Gomes é doutor em administração pública e professor associado do Departamento de Administração da UnB. E-mail: rgomes@unb.br. 